\title{
Antecedents and enablers of supply chain reconfigurability and its effect on performance
}

Slim ZIDI ( $\square$ slim.zidi02@etud.univ-paris8.fr)

Paris 8 University: Universite Paris 8 https://orcid.org/0000-0002-6552-5989

Nadia Hamani

Paris 8 University: Universite Paris 8

Lyes Kermad

Paris 8 University: Universite Paris 8

\section{Research Article}

Keywords: Reconfigurable Supply Chain, Performance Evaluation, Quantitative Factors, Supply Chain Management

Posted Date: October 13th, 2021

DOI: https://doi.org/10.21203/rs.3.rs-964279/v1

License: @ (i) This work is licensed under a Creative Commons Attribution 4.0 International License. Read Full License 


\title{
Antecedents and enablers of supply chain reconfigurability and its effect on performance
}

\author{
Slim ZIDI Corresponding author ${ }^{1,2^{*}}$, Nadia HAMANI ${ }^{2}$, Lyes KERMAD ${ }^{1}$ \\ ${ }^{1}$ University of Paris 8, 140 Rue de la Nouvelle France, Montreuil, France \\ ${ }^{2}$ University of Picardie Jules Verne, 48 Rue d'Ostende, 02100 Saint-Quentin, France
}

*Corresponding Author :

Slim Zidi

Laboratory of QUARTZ (EA 7393), University of Paris 8

Laboratory of Innovative Technologies, University of Picardie Jules Verne

E-mail: slim.zidi02@etud.univ-paris8.fr

ORCID: 0000-0002-6552-5989

\section{Nadia Hamani}

Laboratory of Innovative Technologies, University of Picardie Jules Verne

E-mail : nadia.hamani@u-picardie.fr

ORCID: 0000-0001-6151-2585

Lyes Kermad

Laboratory of QUARTZ (EA 7393), University of Paris 8

E-mail : 1.kermad@iut.univ-paris8.fr

ORCID: 0000-0002-8302-3720 


\title{
Antecedents and enablers of supply chain reconfigurability and its effect on performance
}

\author{
Slim ZIDI Corresponding author ${ }^{1,2[0000-0002-6552-5989]}$, Nadia HAMANI ${ }^{20000-0001-6151-2585]}$, Lyes \\ KERMAD ${ }^{1[0000-0002-8302-3720]}$
}

E-mail corresponding author: slim.zidi02@etud.univ-paris8.fr

${ }^{1}$ University of Paris 8, 140 Rue de la Nouvelle France, Montreuil, France

${ }^{2}$ University of Picardie Jules Verne, 48 Rue d'Ostende, Saint-Quentin, France

\begin{abstract}
The reconfiguration of supply chain is becoming a crucial concept used to deal with market disruptions and changes such as COVID 19 pandemic, demand uncertainty, new technologies, etc. It can be defined as the ability of the supply chain to change its structure and functions in order to adapt to new changes. Its assessment requires an understanding of its quantitative factors to provide indicators that are easy to interpret. Effective reconfigurability assessment can be achieved by measuring quantitatively its six characteristics (modularity, integrability, convertibility, diagnosability, scalability and customization). This paper aims at identifying the quantitative factors of each characteristic and their inter-relationships by using Total Interpretive Structural Modelling (TISM). The structural model obtained by TISM is applied to understand the dependency quantitative factors. Based on TISM results, a classification of quantitative factors is determined using «Matrice d'Impacts Croisés, Multiplication Appliquée à un Classement» (MICMAC) analysis. This paper may be helpful to understand the previously mentioned characteristics of reconfigurable supply chain in order to facilitate the measuring and the assessment of reconfigurability.
\end{abstract}

Keywords: Reconfigurable Supply Chain, Performance Evaluation, Quantitative Factors, Supply Chain Management.

\section{Introduction}

Nowadays, the covid-19 pandemic and many other hazards reveal the inability of the existing supply chains to cope with unforeseen risks. Consequently, several supply chain strategies need to be reconsidered. For example, reshoring is a core element in the supply chain reconfiguration strategy [1,2]. It needs to be reconsidered to deal with the disruptions caused by the COVID 19 pandemic [3, 4]. In addition, supply chain uncertainties, demand fluctuations and technological change are leading manufacturers to adapt the adequate supply that makes them competitive. To meet these challenges, the implementation of a Reconfigurable Supply Chain (RSC) ensures the survival of the company in changing environment $[5,6]$. RSC designates the ability of supply chain to change its structure and its functions to cope with disruptions. The latter are defined as unexpected events that impact the supply chain performance $[7,8]$. Although disruption risks are rare events, they highly affect the supply chain [7, 9-12].

The changes affecting supply chain configuration are related to partner positions within the networks and the role of the central network organization [13]. Reconfiguration in supply chain combines a positive side indicating the innovation and the negative side indicating disruption risks, that is why it is important to innovate for disruption recovery [14]. In fact, the innovation is linked to the implementation of new technologies. Tziantopoulos et al., (2019) showed the crucial role of additive manufacturing technologies in supply chain reconfiguration strategies. RSC ensures the flexibility and agility of the supply chain by altering its configurations with the minimum resources [16]. Reconfigurability is characterized by modularity, convertibility, integrability, diagnosability, 
scalability and customization. [17, 18]. These characteristics result in a truly-reconfigurable supply chain [18]. Hence, it is necessary to assess the degree of reconfigurability through its characteristics to determine if the supply chain can easily and quickly change its structure and functions to cope with disruptions [19, 20]. Several indicators have been proposed to measure reconfigurability for machine, cell and system reconfiguration. However, the measuring of the supply chain capacity to cope with disruptions was not given great interest by the research community. In this paper, the previously mentioned reconfigurability characteristics are considered as the performance indicators for assessing the degree of reconfigurability. This assessment requires the identification of some factors to quantify each characteristic to help decision makers determine the capacity of their supply chains to cope with events that may affect the supply chain performance.

The purpose of this paper is to specify factors related to modularity, convertibility, integrability, diagnosability, scalability and customization, which allows measuring the degree of reconfigurability.

The rest of the paper is organized as follows. In Section 2, the related works are surveyed. Section 3 presents the proposed methodology applied to identify the quantitative factors of each reconfigurability characteristics and analyze the interrelationships between them. The obtained results are discussed in section 4 . Section 5 concludes the paper.

\section{Literature review}

\subsection{The concept of reconfigurability}

Today's market environment is characterized by high competition and rapid change, which drives companies to implement new technologies that offer high flexibility and agility. New technologies are a major advantage for manufacturers in their strategies to adapt to changing market needs. Decision-makers are looking for these technologies to adjust their systems, from a structural and functional point of view to new requirements through dynamic reconfiguration. To remain competitive, manufacturing firms must respond quickly to fluctuating market demand by introducing products that meet customer needs [21]. In fact, the need to introduce new products, changing product structures, fluctuating demand, and the continuous emergence of new technologies have given rise to the concept of "Reconfigurability" manufacturing systems called Reconfigurable Manufacturing System (RMS) characterized by: modularity, integrability, convertibility, diagnosability and scalability [22]. Reconfigurability refers to the practical ability of a production or assembly system to change to a particular number of parts or sub-parts by adding or removing functional elements reactively and with minimal effort and delay [23]. Thus, it refers to the ability to repeatedly modify and reorganize the components of a system [24].

Reconfigurability represents a form of changeability that can be applied at the equipment, production system, and assembly system level to dynamically and efficiently change the capabilities and functionality of the system [2527]. Beyond machines and system components, reconfigurability includes the ability to reconfigure resources quickly and efficiently to generate and deploy new configurations that cope with the new environment [28].

At a higher level, reconfigurability can be applied at the supply chain level. It is defined as the ability of supply chain to change its structure and its functions to cope with disruption and market changes [20]. Indeed, the guarantee of reconfigurability is mainly due to its six characteristics that allow to reduce the reconfiguration effort. $[19,20]$ consider that these characteristics allow to judge and evaluate the capacity of the supply chain to adapt with the new requirements. Therefore, it is necessary to study the analogy between the characteristics at RMS level and those at RSC level.

\subsection{The Characteristics of reconfigurability: from RMS to RSC}

\subsection{Modularity}

Modularity is generally used to reduce the complexity of the system through a decomposition based on the interactions existing between its components. In reconfigurable systems, it is measured through the degree of coupling, which designates the interactions between modules, and cohesion which indicates the interactions within modules [29-35]. The objective of modularity is to maximize cohesion and minimize coupling. In RSCs, modularity aims at clustering the activities of the supply chain by taking into account the flows connecting them. It ensures the independence between modules through the standardization of interfaces [36, 37]. In fact, the supply 
chain modularity is measured by the degree of non-proximity (geographic, organizational, cultural and electronic) [38]. Quantitative factors proposed to measure the degree of modularity are the numbers of modules, the intra and inter modules interactions and the lead time.

\subsection{Convertibility}

To cope with disruptions, the system should be made up of components that can be easily converted to adapt quickly to new changes. In Reconfigurable Manufacturing Systems, convertibility is measured based on the increment of conversion, the routing connections and the replicated machines [39]. The systems capability to be autonomous is also a quantitative factor that must be considered to measure convertibility [40]. To easily convert supply chain components, it is necessary to have redundant entities to quickly deal with disruption [41]. Indeed, supply chain redundancy is the quantitative factor of convertibility measurement in RSC.

\subsection{Integrability}

Adjustment cost and time are key factors in measuring integrability in RMS [35]. They can be reduced by the standardization of interfaces. The complexity of the latter may, in turn, minimize the complexity of the supply chain composed of a set of nodes and flows that represent the connections between nodes [42, 43]. [44] explained the impact of product complexity on supply chain network that can negatively impact collaborative strategies with suppliers in the supply chain. It is due to the large number of actors and interconnections between them [45]. Quantitative factors allowing integrability measurement in RSC are number of nodes and number of connections.

\subsection{Diagnosability}

In order to detect and correct failures quickly, the reconfigurable system must have a high degree of RMS diagnosability that can be measured using the three following parameters:

- Detectability which determines the time before detecting the failure;

- Predictability which measures the time before the failure re-occurrence;

- Distinguishability which measure the time necessary to identify the replaceable unit of a system that causes a failure [31].

Diagnosability is also measured based on the accuracy of the quality tests on products during ramp up time [35]. Indeed, the quality of the information transmitted in the system provides a better visibility on the system' state and, consequently, it allows a rapid detection of failures. In supply chain, this parameter is measured as a function of the quantity, accuracy and freshness of the information [46]. Based on the above reasoning, RSC diagnosability is measured by considering two quantitative factors: supply chain visibility and detection time.

\subsection{Scalability}

In RMS, if the system is able to satisfy the customer demand with small capacity adjustments, then the RMS will have a high scalability and vice versa [35]. Scalability can be measured by the effectiveness of the system [47] and by the adjustment value needed to achieve the maximum capacity which depends on the reconfiguration cost and time [35]. Scalability in the supply chain depends on latency, the ability to achieve performance objectives in a dynamic and uncertain environment and data quality [48]. The impact of scalability on supply chain performance can be expressed by delay [49]. Hence, RSC scalability can be measured by two quantitative factors: latency and throughput capacity.

\subsection{Customization}

Customization depends on customization activities showing customer involvement in the realization of products, which is a key factor that should be considered to measure the degree of customization in the supply chain [50]. Its degree can be increased by minimizing the response time [51, 52]. Indeed, customization can be measured based on several indicators such as [53] the value added time, the throughput rate, the average number of customizable functions, etc. In RMS, two aspects must be taken into account in customization assessment: the product and the functionality which designates the machine utilization rate [35]. Based on this analysis, the quantitative factors of customization measurement are the response time and the number of customized functions. 
As shown in Table 1, the identified quantitative factors of each RSC characteristics are summarized.

Table 1. Quantitative factors of RSC characteristics

\begin{tabular}{|c|c|c|c|}
\hline Characteristics & ID & Quantitative factors & Definition \\
\hline \multirow{3}{*}{ Modularity } & M1 & Number of modules & $\begin{array}{l}\text { The number of modules/units obtained after the modular } \\
\text { decomposition }\end{array}$ \\
\hline & M2 & $\begin{array}{l}\text { Intra- and inter- modules } \\
\text { interactions }\end{array}$ & $\begin{array}{l}\text { The number of links connecting the different modules and } \\
\text { the elements of each module. }\end{array}$ \\
\hline & M3 & Lead time & $\begin{array}{l}\text { Corresponds to the time between the ordering of a supplier } \\
\text { and the delivering of goods to the customer }\end{array}$ \\
\hline Convertibility & $\mathrm{CO} 1$ & Supply chain redundancy & $\begin{array}{l}\text { Consists in providing additional capacity to avoid delays } \\
\text { or stops due to disruptions }\end{array}$ \\
\hline \multirow[t]{2}{*}{ Integrability } & I1 & Number of nodes & $\begin{array}{l}\text { Refers to the number of companies coordinating the } \\
\text { management of goods (purchase, stock, transport...) } \\
\text { within the same supply chain }\end{array}$ \\
\hline & $\mathrm{I} 2$ & Number of connections & $\begin{array}{l}\text { Refers to the number of interactions between the nodes of } \\
\text { the supply chain }\end{array}$ \\
\hline \multirow[b]{2}{*}{ Diagnosability } & D1 & Supply chain visibility & $\begin{array}{l}\text { Is the sharing of information in a just-in-time, reliable and } \\
\text { accurate manner }\end{array}$ \\
\hline & D2 & Detection time & $\begin{array}{l}\text { The time measured from the moment when a company } \\
\text { realizes that it will be affected by a supply chain } \\
\text { disruption to the moment in which the incident really } \\
\text { occurs }\end{array}$ \\
\hline \multirow[t]{2}{*}{ Scalability } & S1 & Latency & $\begin{array}{l}\text { It is the ratio between the delivery time and the throughput } \\
\text { time }\end{array}$ \\
\hline & $\mathrm{S} 2$ & Throughput capacity & Designates the number of the performed orders. \\
\hline \multirow{2}{*}{ Customization } & CU1 & Response time & $\begin{array}{l}\text { It is the total amount of time spent to respond to a request } \\
\text { for service }\end{array}$ \\
\hline & CU2 & $\begin{array}{l}\text { Number of customized } \\
\text { functions }\end{array}$ & $\begin{array}{l}\text { Designates the number of functions related to the } \\
\text { customization of the product/service }\end{array}$ \\
\hline
\end{tabular}

\section{Proposed approach}

Literature studies were carried out to identify factors for a quantitative measure of reconfigurability characteristics. Based on the results presented in the literature review, the first stage of the proposed approach is to determine the interactions between all the quantitative factors of each RSC characteristics using TISM method. An interaction is a mutual or reciprocal action or influence. It can be related to the enterprise internal flows and external flows linking all supply chain actors. These flows can be physical, informational and financial. The second stage consists in identifying the most important quantitative factors. This classification allows identifying the most important characteristics in the supply chain reconfiguration process. Figure 1 shows the different steps of our approach. 


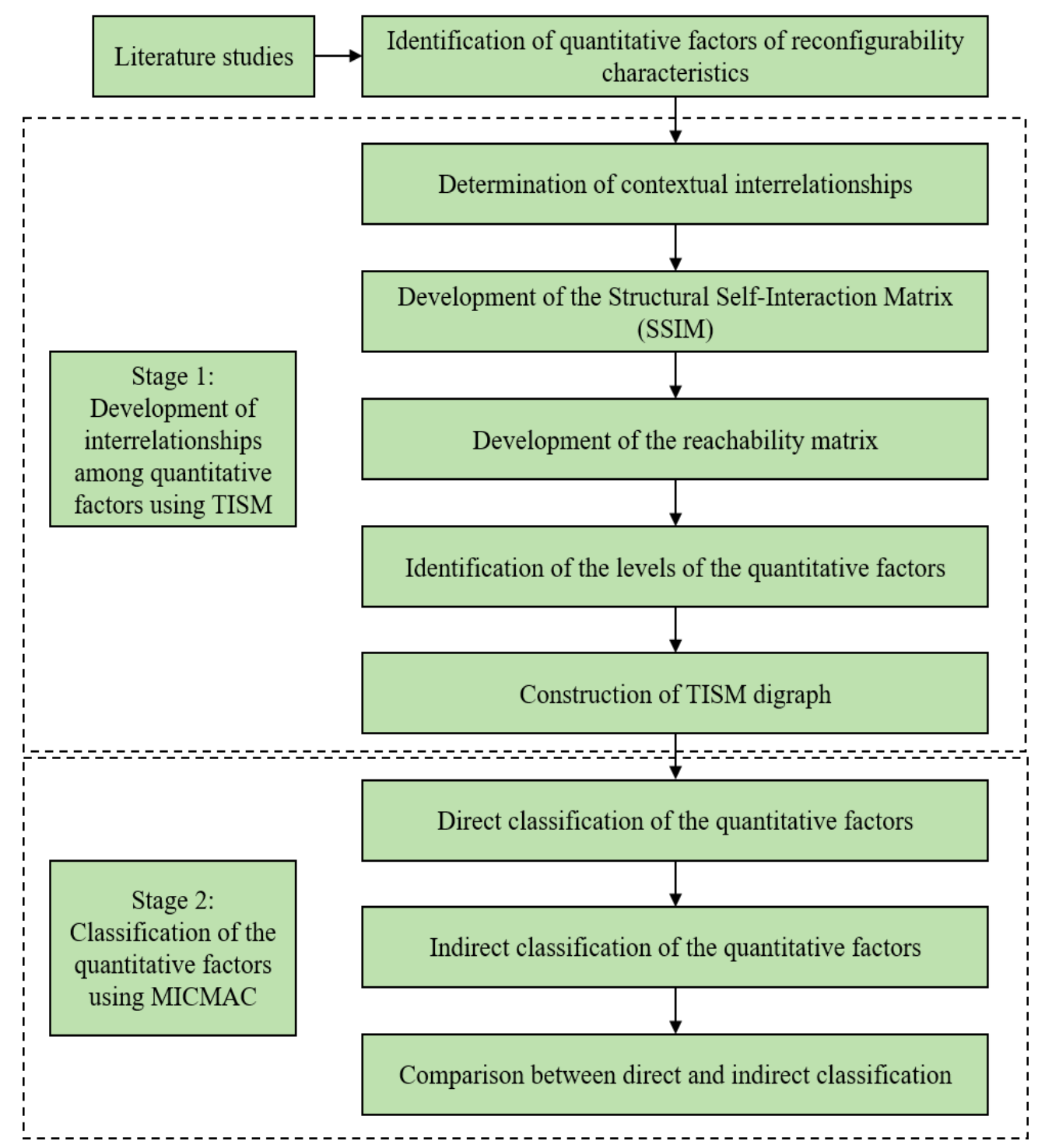

Fig 1 Proposed approach of identification and analysis of the quantitative factors of RSC characteristics

\subsection{Development of interrelationships among the quantitative factors using TISM}

The TISM method is applied to identify contextual relationships between the identified quantitative factors. It consists in defining the relationships between the quantitative factors, by developing structural and reachability matrices in order to classify the quantitative factors according to different levels.

\section{Development of the Structural Self-Interaction Matrix (SSIM)}

To determine the influences between the quantitative factors related to each reconfigurability characteristic, a questionnaire was conducted and addressed to a group of experts and academics. The questionnaire is used to analyze the influences between the identified factors, and thus to build SSIM. 11 experts and academics participated in the questionnaire, where $36.4 \%$ have less than 10 years of experience, $36.4 \%$ also have experience between 10 and 20 years, while $27.3 \%$ have more than 20 years of experience. A classification of the experts' profiles is presented in Table 2.

Table 2. Expert's profile

\begin{tabular}{lll}
\hline Profile & Category & Number of experts \\
\hline Experience & Less than 10 years & $36.4 \%$
\end{tabular}


Between 10 and 20 years

More than 20 years

Field
Supply chain

Transport

Production

Academic
$36.4 \%$

$27.3 \%$

$90.9 \%$

$72.7 \%$

$54.5 \%$

$18.2 \%$

This matrix is used to define any relationship between two quantitative factors. Four symbols are employed to indicate the direction of the relationship $(i, j)$, as shown in Table 3 , with:

- V means that the quantitative factor $\mathrm{i}$ "will influence" the quantitative factor $\mathrm{j}$;

- A indicates that the quantitative factor $\mathrm{i}$ "is influenced" by the quantitative factor $\mathrm{j}$;

- $\mathrm{X}$ shows that the quantitative factors $\mathrm{i}$ and $\mathrm{j}$ influence each other;

- O reveals that the quantitative factors $\mathrm{i}$ and $\mathrm{j}$ are not related.

Table 3. Formation of SSIM

\begin{tabular}{|c|c|c|c|c|c|c|c|c|c|c|c|c|}
\hline & CU2 & CU1 & D2 & D1 & S2 & S1 & $\mathrm{CO} 1$ & $\mathrm{I} 2$ & I1 & M3 & M2 & M1 \\
\hline M1 & $\mathrm{V}$ & $\mathrm{V}$ & $\mathrm{V}$ & $\mathrm{V}$ & $\mathrm{V}$ & $\mathrm{V}$ & $\mathrm{V}$ & $X$ & $X$ & $\mathrm{~V}$ & $X$ & $X$ \\
\hline M2 & $\mathrm{V}$ & $\mathrm{V}$ & $\mathrm{V}$ & $\mathrm{V}$ & $\mathrm{V}$ & $\mathrm{V}$ & $\mathrm{V}$ & $X$ & $X$ & $\mathrm{~V}$ & $X$ & \\
\hline M3 & A & A & $\mathrm{O}$ & $\mathrm{O}$ & $X$ & $X$ & $\mathrm{O}$ & A & A & $X$ & & \\
\hline I1 & $\mathrm{V}$ & $\mathrm{V}$ & $\mathrm{V}$ & $\mathrm{V}$ & $\mathrm{V}$ & $\mathrm{V}$ & $\mathrm{V}$ & $X$ & $X$ & & & \\
\hline I2 & $\mathrm{V}$ & $\mathrm{V}$ & $\mathrm{V}$ & $\mathrm{V}$ & $\mathrm{V}$ & $\mathrm{V}$ & $\mathrm{V}$ & $X$ & & & & \\
\hline $\mathrm{CO} 1$ & $\mathrm{O}$ & $\mathrm{O}$ & $\mathrm{V}$ & $\mathrm{V}$ & $\mathrm{O}$ & $\mathrm{O}$ & $X$ & & & & & \\
\hline S1 & $\mathrm{O}$ & $\mathrm{O}$ & $\mathrm{O}$ & $\mathrm{O}$ & $X$ & $X$ & & & & & & \\
\hline $\mathrm{S} 2$ & $\mathrm{O}$ & $\mathrm{O}$ & $\mathrm{O}$ & $\mathrm{O}$ & $X$ & & & & & & & \\
\hline D1 & $\mathrm{V}$ & $\mathrm{V}$ & X & $X$ & & & & & & & & \\
\hline D2 & $\mathrm{V}$ & $\mathrm{V}$ & $\mathrm{X}$ & & & & & & & & & \\
\hline CU1 & $X$ & $X$ & & & & & & & & & & \\
\hline CU2 & $X$ & & & & & & & & & & & \\
\hline
\end{tabular}

\section{Development of the reachability matrix}

Based on the SSIM, we replace V, A, X and O by 1 or 0 . The applied conversion rules are presented below:

- If the (i,j) entry in the SSIM is $V$, then the $(i, j)$ entry in the reachability matrix is 1 and the $(j, i)$ entry is 0 ;

- If the $(i, j)$ entry in the SSIM is A, then the $(i, j)$ entry in the reachability matrix is 0 and the $(j, i)$ entry is 1 ;

- If the $(i, j)$ entry in the SSIM is $X$, then the $(i, j)$ and $(j, i)$ entry in the reachability matrix is 1 ;

- If the $(i, j)$ entry in the SSIM is $O$, then the $(i, j)$ and $(j, i)$ entry in the reachability matrix is 0 .

The transitivity is also checked in the rules of the matrix. If a relationship exists between the first and second variable and between the second and third variable, then there is a relationship between the first and third variable. The obtained matrices are presented in Table 4 and Table 5.

Table 4. Initial reachability matrix

\begin{tabular}{ccccccccccccc}
\hline & M1 & M2 & M3 & I1 & I2 & CO1 & S1 & S2 & D1 & D2 & CU1 & CU2 \\
\hline M1 & 1 & 1 & 1 & 1 & 1 & 1 & 1 & 1 & 1 & 1 & 1 & 1 \\
M2 & 1 & 1 & 1 & 1 & 1 & 1 & 1 & 1 & 1 & 1 & 1 & 1 \\
M3 & 0 & 0 & 1 & 0 & 0 & 0 & 1 & 1 & 0 & 0 & 0 & 0 \\
I1 & 1 & 1 & 1 & 1 & 1 & 1 & 1 & 1 & 1 & 1 & 1 & 1 \\
I2 & 1 & 1 & 1 & 1 & 1 & 1 & 1 & 1 & 1 & 1 & 1 & 1 \\
CO1 & 0 & 0 & 0 & 1 & 1 & 1 & 0 & 0 & 1 & 1 & 0 & 0 \\
S1 & 0 & 0 & 1 & 0 & 0 & 0 & 1 & 1 & 0 & 0 & 0 & 0 \\
S2 & 0 & 0 & 1 & 0 & 0 & 0 & 1 & 1 & 0 & 0 & 0 & 0 \\
D1 & 0 & 0 & 0 & 0 & 0 & 0 & 0 & 0 & 1 & 1 & 1 & 1 \\
D2 & 0 & 0 & 0 & 0 & 0 & 0 & 0 & 0 & 1 & 1 & 1 & 1
\end{tabular}




\begin{tabular}{lllllllllllll} 
CU1 & 0 & 0 & 1 & 0 & 0 & 0 & 0 & 0 & 0 & 0 & 1 & 1 \\
CU2 & 0 & 0 & 1 & 0 & 0 & 0 & 0 & 0 & 0 & 0 & 1 & 1 \\
\hline
\end{tabular}

Table 5. Final Reachability matrix

\begin{tabular}{ccccccccccccc}
\hline & M1 & M2 & M3 & I1 & I2 & CO1 & S1 & S2 & D1 & D2 & CU1 & CU2 \\
\hline M1 & 1 & 1 & 1 & 1 & 1 & 1 & 1 & 1 & 1 & 1 & 1 & 1 \\
M2 & 1 & 1 & 1 & 1 & 1 & 1 & 1 & 1 & 1 & 1 & 1 & 1 \\
M3 & 0 & 0 & 1 & 0 & 0 & 0 & 1 & 1 & 0 & 0 & 0 & 0 \\
I1 & 1 & 1 & 1 & 1 & 1 & 1 & 1 & 1 & 1 & 1 & 1 & 1 \\
I2 & 1 & 1 & 1 & 1 & 1 & 1 & 1 & 1 & 1 & 1 & 1 & 1 \\
CO1 & $1^{*}$ & $1^{*}$ & $1^{*}$ & 1 & 1 & 1 & $1^{*}$ & $1^{*}$ & 1 & 1 & $1^{*}$ & $1^{*}$ \\
S1 & 0 & 0 & 1 & 0 & 0 & 0 & 1 & 1 & 0 & 0 & 0 & 0 \\
S2 & 0 & 0 & 1 & 0 & 0 & 0 & 1 & 1 & 0 & 0 & 0 & 0 \\
D1 & 0 & 0 & $1^{*}$ & 0 & 0 & 0 & 0 & 0 & 1 & 1 & 1 & 1 \\
D2 & 0 & 0 & $1^{*}$ & 0 & 0 & 0 & 0 & 0 & 1 & 1 & 1 & 1 \\
CU1 & 0 & 0 & 1 & 0 & 0 & 0 & $1^{*}$ & $1^{*}$ & 0 & 0 & 1 & 1 \\
CU2 & 0 & 0 & 1 & 0 & 0 & 0 & $1^{*}$ & $1^{*}$ & 0 & 0 & 1 & 1 \\
\hline
\end{tabular}

Identification of the levels of the quantitative factors

The obtained accessibility matrix is divided into reachability and antecedent sets, as shown in Table 6, Table 7 , Table 8 and Table 9.

Table 6. Level partition (Iteration I)

\begin{tabular}{lllll}
\hline Factors & Reachability set & Antecedent set & Intersection set & Level \\
\hline M1 & M1,M2,M3,I1,I2,CO1,S1,S2,D1,D & M1,M2,I1,I2,CO1 & M1,M2,I1,I2,CO1 \\
M2 & 2,CU1,CU2 & & \\
& 2,CU1,CU2,M3,I1,I2,CO1,S1,S2,D1,D & M1,M2,I1,I2,CO1 & M1,M2,I1,I2,CO1 \\
M3 & M3,S1,S2 & M1,M2,M3,I1,I2,CO1,S1, & M3,S1,S2 & I \\
I1 & M1,M2,M3,I1,I2,CO1,S1,S2,D1,D & M1,M2,I1,I2,CO1 & M1,M2,I1,I2,CO1 \\
& 2,CU1,CU2 & & \\
I2 & M1,M2,M3,I1,I2,CO1,S1,S2,D1,D & M1,M2,I1,I2,CO1 & M1,M2,I1,I2,CO1 \\
& 2,CU1,CU2 & & \\
CO1 & M1,M2,M3,I1,I2,CO1,S1,S2,D1,D & M1,M2,I1,I2,CO1 & M1,M2,I1,I2,CO1 \\
& 2,CU1,CU2 & M1,M2,M3,I1,I2,CO1,S1, & M3,S1,S2, \\
S1 & M3,S1,S2, & S2,CU1,CU2 & I \\
& & M1,M2,M3,I1,I2,CO1,S1, & M3,S1,S2, \\
S2 & M3,S1,S2, & S2,CU1,CU2 & I \\
& & M1,M2,I1,I2,CO1,D1,D2 & D1,D2 \\
D1 & M3,D1,D2,CU1,CU2 & M1,M2,I1,I2,CO1,D1,D2 & D1,D2 \\
D2 & M3,D1,D2,CU1,CU2 & M1,M2,I1,I2,CO1,D1,D2, & CU1,CU2 \\
CU1 & M3,S1,S2,CU1,CU2 & CU1,CU2 & \\
& & M1,M2,I1,I2,CO1,D1,D2, & CU1,CU2 \\
CU2 & M3,S1,S2,CU1,CU2 & CU1,CU2 & \\
& & & \\
& & &
\end{tabular}

Table 7. Level partition (Iteration II)

\begin{tabular}{lllll}
\hline Factors & Reachability set & Antecedent set & Intersection set & Level \\
\hline M1 & M1,M2,I1,I2,CO1,D1,D2,CU1,CU & M1,M2,I1,I2,CO1 & M1,M2,I1,I2,CO1 \\
& 2 & & \\
M2 & M1,M2,I1,I2,CO1,D1,D2,CU1,CU & M1,M2,I1,I2,CO1 & M1,M2,I1,I2,CO1
\end{tabular}




\begin{tabular}{|c|c|c|c|c|}
\hline I1 & $\begin{array}{l}\text { M1,M2,I1,I2,CO1,D1,D2,CU1,CU } \\
2\end{array}$ & $\mathrm{M} 1, \mathrm{M} 2, \mathrm{I} 1, \mathrm{I} 2, \mathrm{CO} 1$ & $\mathrm{M} 1, \mathrm{M} 2, \mathrm{I} 1, \mathrm{I} 2, \mathrm{CO} 1$ & \\
\hline $\mathrm{I} 2$ & $\begin{array}{l}\text { M1,M2,I1,I2,CO1,D1,D2,CU1,CU } \\
2\end{array}$ & $\mathrm{M} 1, \mathrm{M} 2, \mathrm{I} 1, \mathrm{I} 2, \mathrm{CO} 1$ & $\mathrm{M} 1, \mathrm{M} 2, \mathrm{I} 1, \mathrm{I} 2, \mathrm{CO} 1$ & \\
\hline $\mathrm{CO} 1$ & $\begin{array}{l}\mathrm{M} 1, \mathrm{M} 2, \mathrm{I} 1, \mathrm{I} 2, \mathrm{CO} 1, \mathrm{D} 1, \mathrm{D} 2, \mathrm{CU} 1, \mathrm{CU} \\
2\end{array}$ & $\mathrm{M} 1, \mathrm{M} 2, \mathrm{I} 1, \mathrm{I} 2, \mathrm{CO} 1$ & $\mathrm{M} 1, \mathrm{M} 2, \mathrm{I} 1, \mathrm{I} 2, \mathrm{CO} 1$ & \\
\hline D1 & D1,D2,CU1,CU2 & M1,M2,I1,I2,CO1,D1,D2 & D1,D2 & \\
\hline D2 & D1,D2,CU1,CU2 & $\mathrm{M} 1, \mathrm{M} 2, \mathrm{I} 1, \mathrm{I} 2, \mathrm{CO} 1, \mathrm{D} 1, \mathrm{D} 2$ & D1,D2 & \\
\hline CU1 & CU1,CU2 & $\begin{array}{l}\text { M1,M2,I1,I2,CO1,D1,D2, } \\
\text { CU1,CU2 }\end{array}$ & CU1,CU2 & II \\
\hline CU2 & CU1,CU2 & $\begin{array}{l}\text { M1,M2,I1,I2,CO1,D1,D2, } \\
\text { CU1,CU2 }\end{array}$ & CU1,CU2 & II \\
\hline
\end{tabular}

Table 8. Level partition (Iteration III)

\begin{tabular}{lllll}
\hline Factors & Reachability set & Antecedent set & Intersection set & Level \\
\hline M1 & M1,M2,I1,I2,CO1,D1,D2 & M1,M2,I1,I2,CO1 & M1,M2,I1,I2,CO1 & IV \\
M2 & M1,M2,I1,I2,CO1,D1,D2 & M1,M2,I1,I2,CO1 & M1,M2,I1,I2,CO1 & IV \\
I1 & M1,M2,I1,I2,CO1,D1,D2 & M1,M2,I1,I2,CO1 & M1,M2,I1,I2,CO1 & IV \\
I2 & M1,M2,I1,I2,CO1,D1,D2 & M1,M2,I1,I2,CO1 & M1,M2,I1,I2,CO1 & IV \\
CO1 & M1,M2,I1,I2,CO1,D1,D2 & M1,M2,I1,I2,CO1 & M1,M2,I1,I2,CO1 & IV \\
D1 & D1,D2 & M1,M2,I1,I2,CO1,D1,D2 & D1,D2 & III \\
D2 & D1,D2 & M1,M2,I1,I2,CO1,D1,D2 & D1,D2 & III \\
\hline
\end{tabular}

Table 9. Level partition (Iteration IV)

\begin{tabular}{lllll}
\hline Factors & Reachability set & Antecedent set & Intersection set & Level \\
\hline M1 & M1,M2,I1,I2,CO1 & M1,M2,I1,I2,CO1 & M1,M2,I1,I2,CO1 & IV \\
M2 & M1,M2,I1,I2,CO1 & M1,M2,I1,I2,CO1 & M1,M2,I1,I2,CO1 & IV \\
I1 & M1,M2,I1,I2,CO1 & M1,M2,I1,I2,CO1 & M1,M2,I1,I2,CO1 & IV \\
I2 & M1,M2,I1,I2,CO1 & M1,M2,I1,I2,CO1 & M1,M2,I1,I2,CO1 & IV \\
CO1 & M1,M2,I1,I2,CO1 & M1,M2,I1,I2,CO1 & M1,M2,I1,I2,CO1 & IV \\
\hline
\end{tabular}

\section{TISM model}

Quantitative factors are organized graphically in levels and directed links are represented according to the relationships identified in the Reachability Matrix. The relationship between elements $i$ and $j$ can be represented by an arc from $i$ to $j$. Figure 2 shows the structure of quantitative factors. 


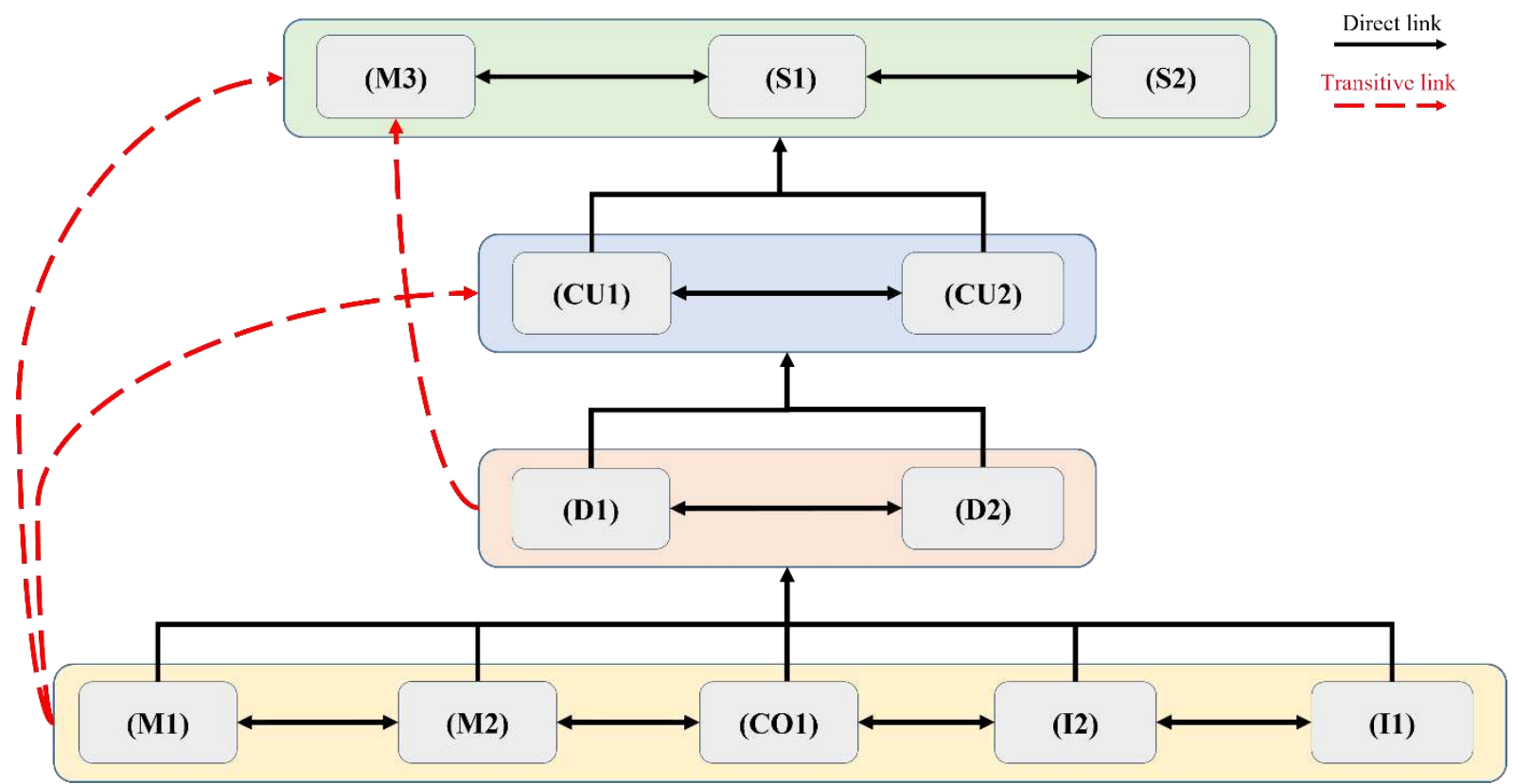

Fig 2 TISM model for the quantitative factors the RSC characteristics

The number of modules, the number of interactions, the number of nodes, the number of inter- and intra-module interactions and the supply chain redundancy are put at the bottom of the model, which means that these factors affect other factors and are not affected by none of them and are not influenced by any factors. Thus, they are very important and need to be primarily taken into account for a better reconfigurability in supply chains. At a higher level, supply chain visibility and detection time represents the second level. These factors interact with the next block constituted by the response time and the number of customized functions that represent the third level, which are homogeneous and influence each other. Finally, the lead time, latency and throughput capacity are in the highest level of the TISM graph. Indeed, they are influenced by all the other enablers, and they affect them slightly.

\subsection{Classification of the quantitative factors using MICMAC analysis}

This stage consists in identifying the quantitative factors, i.e., those that are essential for the development of the system, first by direct classification (easy to implement) and then, by indirect classification (by MICMAC). The MICMAC analysis is used to classify and validate the factors identified in the TISM.

\section{Direct classification of the quantitative factors}

This step consists in filling the matrix of the direct influences, as shown in Table 6. Each element of this matrix is filled in according to the following scale:

- 0 means No influence;

- 1 means Weak influence;

- 2 means Medium influence;

- 3 means Strong influence.

A first set of information can be obtained by analyzing the direct influences using the Direct Impact Matrix. The sum of the values of each row and columns indicates respectively the driving power and the dependency levels, as shown in Table 10.

Table 10. Direct Influence Matrix

\begin{tabular}{|c|c|c|c|c|c|c|c|c|c|c|c|c|c|}
\hline & M1 & M2 & M3 & I1 & $\mathrm{I} 2$ & $\mathrm{CO} 1$ & $\mathrm{~S} 1$ & $\mathrm{~S} 2$ & D1 & D2 & CU1 & CU2 & Sum \\
\hline M1 & 0 & 3 & 3 & 3 & 3 & 3 & 1 & 1 & 2 & 2 & 1 & 1 & 22 \\
\hline M2 & 1 & 0 & 1 & 1 & 1 & 1 & 1 & 1 & 2 & 2 & 1 & 1 & 22 \\
\hline
\end{tabular}




\begin{tabular}{llllllllllllll}
\hline M3 & 0 & 0 & 0 & 0 & 0 & 0 & 1 & 1 & 0 & 0 & 0 & 0 & 6 \\
I1 & 3 & 3 & 2 & 0 & 3 & 2 & 1 & 1 & 3 & 2 & 1 & 1 & 24 \\
I2 & 3 & 3 & 2 & 3 & 0 & 2 & 1 & 1 & 3 & 2 & 1 & 1 & 24 \\
CO1 & 3 & 3 & 3 & 2 & 2 & 0 & 1 & 1 & 2 & 1 & 1 & 1 & 24 \\
S1 & 0 & 0 & 2 & 0 & 0 & 0 & 0 & 3 & 0 & 0 & 0 & 0 & 5 \\
S2 & 0 & 0 & 2 & 0 & 0 & 0 & 3 & 0 & 0 & 0 & 0 & 0 & 5 \\
D1 & 0 & 0 & 1 & 0 & 0 & 0 & 0 & 0 & 0 & 3 & 1 & 1 & 6 \\
D2 & 0 & 0 & 1 & 0 & 0 & 0 & 0 & 0 & 3 & 0 & 1 & 1 & 6 \\
CU1 & 0 & 0 & 1 & 0 & 0 & 0 & 1 & 1 & 0 & 0 & 0 & 3 & 6 \\
CU2 & 0 & 0 & 1 & 0 & 0 & 0 & 1 & 1 & 0 & 0 & 3 & 0 & 6 \\
Sum & 12 & 12 & 21 & 11 & 11 & 10 & 17 & 17 & 13 & 12 & 10 & 10 & \\
\hline
\end{tabular}

The results of the direct influence matrix show that M1 (number of modules), M2 (number of inter- and intramodule interactions), I1 (number of nodes), I2 (number of interactions) and CO1 (supply chain redundancy) have the highest line sums, then they represent the independent factors. In fact, M3 (Lead-time), S1 (Latency) and S2 (Throughput capacity) are dependent factors as they have the highest column sums.

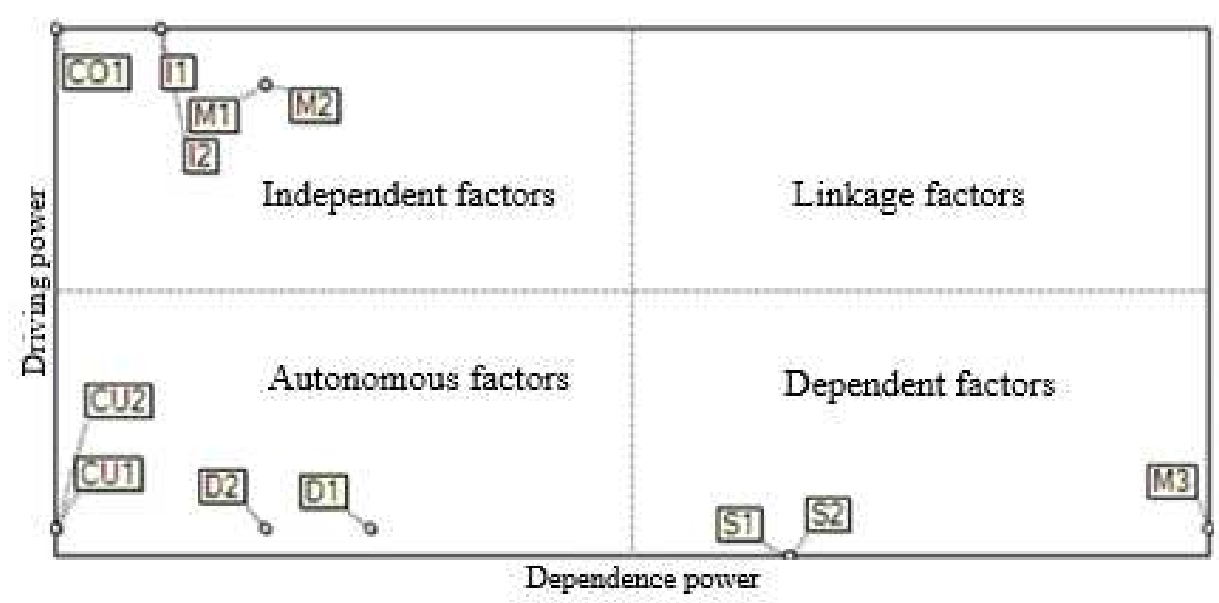

Fig 3 Direct influence/dependence map 


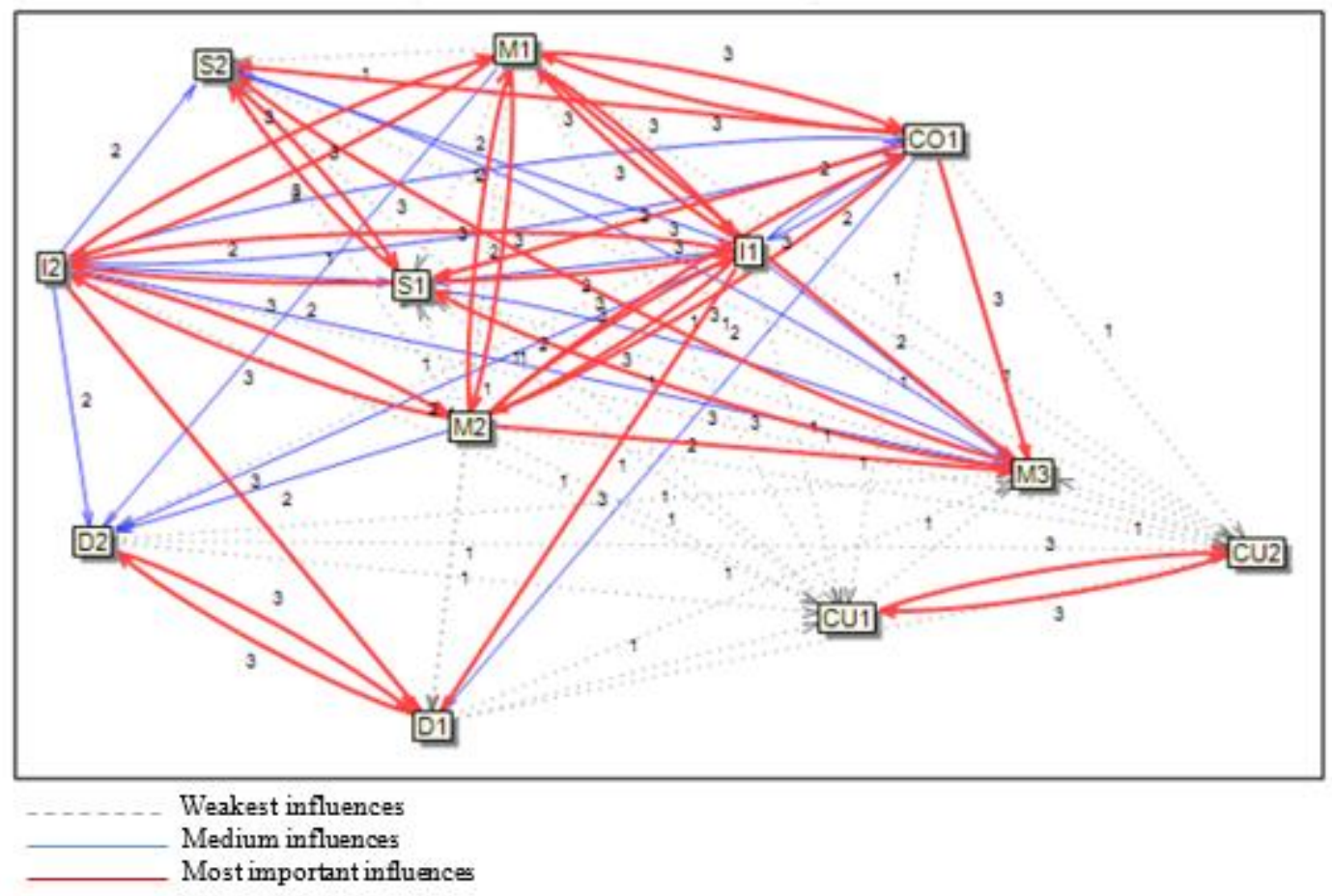

Fig 4 Graph representing direct influence

Figure 3 shows the four quadrants indicating the four categories of factors obtained by the MICMAC analysis. The first quadrant includes the autonomous factors with low influence and low dependency such as D1 (Supply chain visibility), D2 (Detection time), CU1 (Response time) and CU2 (Number of customized functions). The second quadrant contains the dependent factors M3 (Lead time), S1 (Latency), S2 (Throughput capacity) having a low driving power and a high dependency power. The third quadrant contains no factors which consists of the linking factors having high driving and dependency power. The fourth quadrant involves the independent factors with high influence and low dependency, such as M1 (number of modules), M2 (intra- and inter- modules interactions), I1 (number of nodes), I2 (number of connections between nodes) and CO1 (Supply chain redundancy). From the direct influence matrix, MICMAC generates a graph showing the most important influences, as shown in Figure 4.

\section{Indirect classification of the quantitative factors}

The analysis of the indirect relationships allows detecting the essential and hidden factors and classifying the variables according to their influences by considering the global network of the relations described by the structural analysis matrix. The MICMAC analysis examines the influences between the variables to determine the indirect effects. These results show that the enablers M1 (number of modules), M2 (number of interactions between and within modules), I1 (number of nodes), I2 (number of interactions) and CO1 (Supply chain redundancy) are driving enablers since they have the largest sum of lines. While M3 (lead time), S1 (Latency) and S2 (throughput capacity) are the most influenced enablers (also called dependent enablers) because they have the highest sum of column. Table 11 summarizes the obtained results.

Table 11. Driving and dependency power values of the indirect influence matrix

\begin{tabular}{ccc}
\hline & Rows total & Columns total \\
\hline M1 & 4214 & 1494 \\
M2 & 4214 & 1494 \\
M3 & 162 & 3077 \\
I1 & 3772 & 1292 \\
I2 & 4046 & 1399 \\
CO1 & 4046 & 1399 \\
S1 & 206 & 1669
\end{tabular}




\begin{tabular}{ccc} 
S2 & 206 & 1582 \\
D1 & 141 & 2807 \\
D2 & 141 & 2807 \\
CU1 & 186 & 1250 \\
CU2 & 186 & 1250 \\
& 156 & 156 \\
\hline
\end{tabular}

These results reveal that the enablers M1 (number of modules), M2 (number of inter- and intra-module interactions), I1 (number of nodes), I2 (number of interactions) and CO1 (Supply chain redundancy) are driving enablers as they have the largest sums of lines. On the other hand, M3 (lead time), I1 (Latency) and I2 (throughput capacity) are the most influenced enablers (also called dependent enablers) because they have the highest column sums.

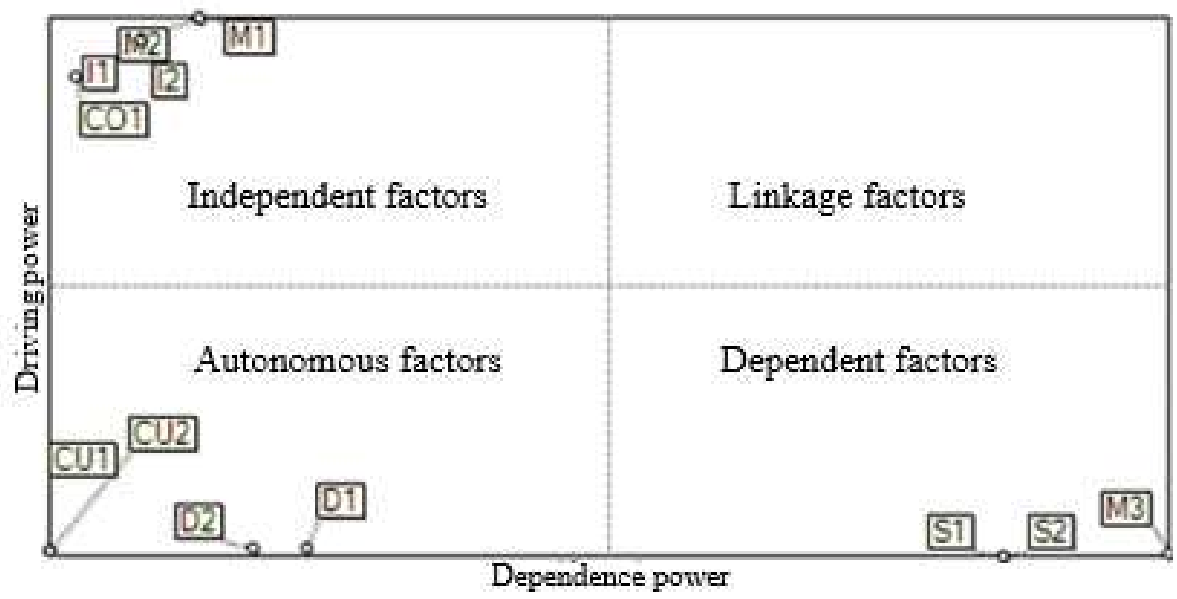

Fig 5 Indirect influence/dependence map

The influential enablers and linking enablers are the same as those of the direct influence map. According to the indirect influence design, all factors keep the same position as in the direct design as demonstrated in Figure 5. The influences of all the factors are represented in Figure 6. 


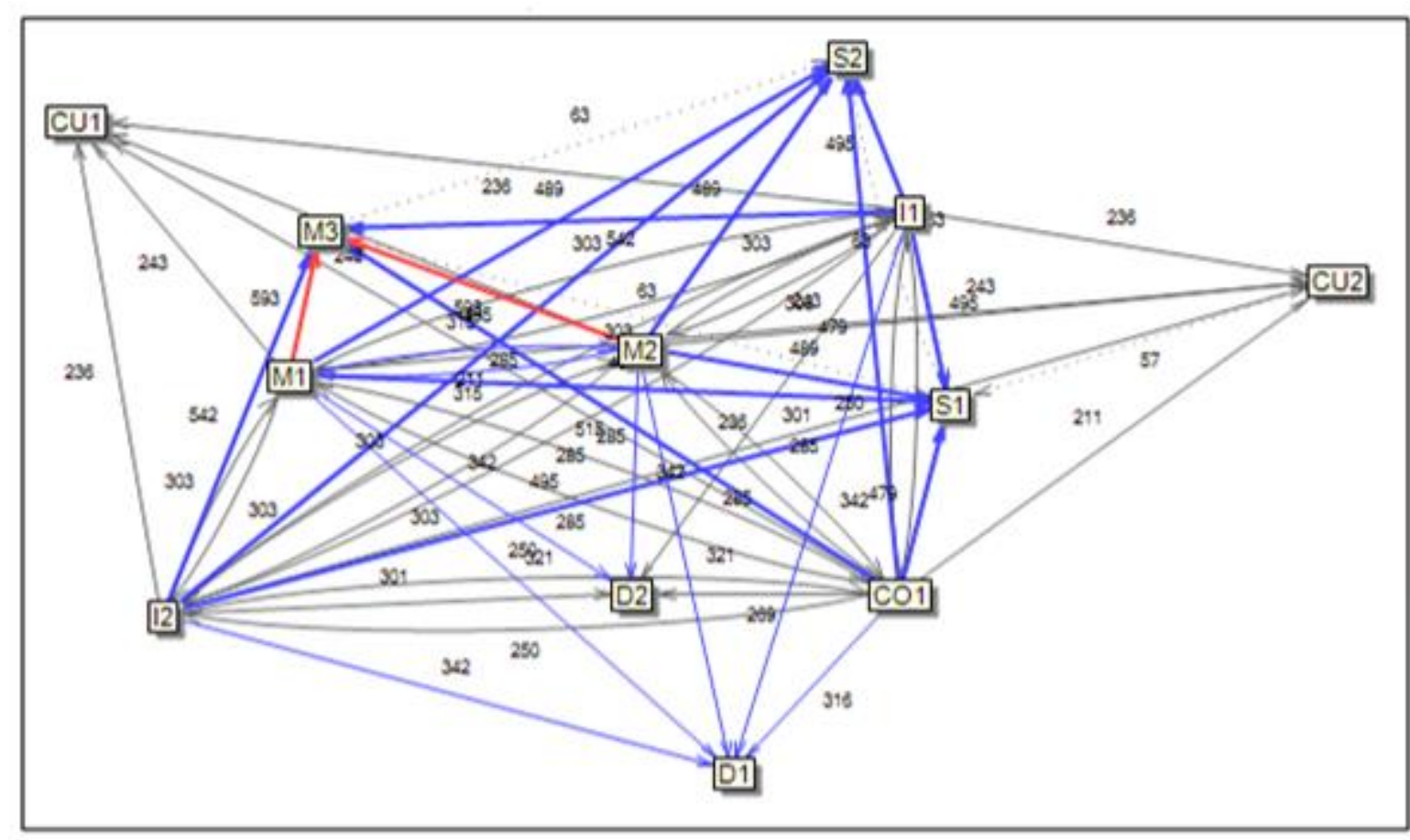

Very weakest influences

Weakest influences

Medium influences

Most important influences

Fig 6 The graph representing indirect influence

\section{Comparison between direct and indirect classification}

A comparison of the hierarchy of the quantitative factors of supply chain reconfigurability in the different classifications (direct and indirect) validates the importance of certain factors such as number of nodes, number of connections, number of modules and supply chain redundancy in in the supply chain reconfigurability assessment process.

MICMAC allows calculating numerical weights (direct influences/dependencies and indirect influences/dependencies) of reconfigurability enablers in supply chains and classifying them in descending order, as exposed in Table 12 and Table 13.

Table 12. Numerical factor weights of direct influences/dependencies

\begin{tabular}{cccc}
\hline Factors & Direct Influence & Factors & Direct dependency \\
\hline CO1 & 1538 & M3 & 1346 \\
I1 & 1538 & S1 & 1089 \\
I2 & 1538 & S2 & 1089 \\
M1 & 1410 & D1 & 833 \\
M2 & 1410 & M1 & 769 \\
M3 & 384 & M2 & 769 \\
D1 & 384 & D2 & 769 \\
D2 & 384 & I1 & 705 \\
CU1 & 384 & I2 & 705 \\
CU2 & 384 & CO1 & 641 \\
S1 & 320 & CU1 & 641 \\
S2 & 320 & CU2 & 641 \\
\hline
\end{tabular}


Table 13. Numerical factor weights for indirect influences/dependencies

\begin{tabular}{cccc}
\hline Factors & Indirect Influence & Factors & Indirect dependency \\
\hline M1 & 1958 & M3 & 1429 \\
M2 & 1958 & S1 & 1304 \\
I1 & 1880 & S2 & 1304 \\
I2 & 1880 & $\mathrm{D} 1$ & 775 \\
CO1 & 1752 & D2 & 735 \\
D1 & 95 & M1 & 694 \\
D2 & 95 & M2 & 694 \\
CU1 & 86 & I1 & 650 \\
CU2 & 86 & I2 & 650 \\
M3 & 75 & CO1 & 600 \\
S1 & 65 & CU1 & 580 \\
S2 & 65 & CU2 & 580 \\
\hline
\end{tabular}

From this comparison, we notice that enablers do not keep their rankings in the classification according to direct and indirect influences and dependencies. Factors M1, M2, D1, D2, CU1 and CU2 have changed their rank in the indirect influence classification and have moved to higher ranks, which prove the importance of the indirect effect of these factors on the other factors. The green lines show the advancement in rank of the factors, while the red lines indicate its degradation. Moreover, we notice that the factors CO1, I1, I2, and M3 moved to lower ranks in the indirect influence classification. The influence of this factor decreases relatively when the indirect influences are considered. This classification allowed clarifying and validating the classification of factors obtained with TISM. Figure 7 represents the most highly reclassified factors and the rank variations for the most dependent factors. The variation in the positions of the enablers between their initial positions and their final positions is shown in Figure 8.

\begin{tabular}{|c|c|}
\hline Rang & Variable \\
\hline 1 & $4 \cdot \mathrm{CO} 1$ \\
\hline 2 & $5 \cdot \mathrm{I} 1$ \\
\hline 3 & $6 \cdot 12$ \\
\hline 4 & $1 \cdot \mathrm{M} 1$ \\
\hline 5 & $2 \cdot \mathrm{M} 2$ \\
\hline 6 & $3 \cdot \mathrm{M} 3$ \\
\hline 7 & $7 \cdot \mathrm{D} 1$ \\
\hline 8 & $8 \cdot \mathrm{D} 2$ \\
\hline 9 & $11 \cdot \mathrm{CU} 1$ \\
\hline 10 & $12 \cdot \mathrm{CU} 2$ \\
\hline 11 & $9 \cdot \mathrm{S} 1$ \\
\hline 12 & $10 \cdot \mathrm{S} 2$ \\
\hline
\end{tabular}

a. Classification of factors according to their influences

\begin{tabular}{|c|c|}
\hline Rang & Variable \\
\hline 1 & $3 \cdot \mathrm{M} 3$ \\
\hline 2 & $9 \cdot \mathrm{S} 1$ \\
\hline 3 & $10 \cdot \mathrm{S} 2$ \\
\hline 4 & $7 \cdot \mathrm{D} 1$ \\
\hline 5 & $1 \cdot \mathrm{M} 1$ \\
\hline 6 & $2 \cdot \mathrm{M} 2$ \\
\hline 7 & $8 \cdot \mathrm{D} 2$ \\
\hline 8 & $5 \cdot \mathrm{I} 1$ \\
\hline 9 & $6 \cdot \mathrm{I}$ \\
\hline 10 & $4 \cdot \mathrm{CO} 1$ \\
\hline 11 & $11 \cdot \mathrm{CU} 1$ \\
\hline 12 & $12 \cdot \mathrm{CU} 2$ \\
\hline
\end{tabular}

b. Classification of factors according to their dependencies

Fig 7 Factors classification 


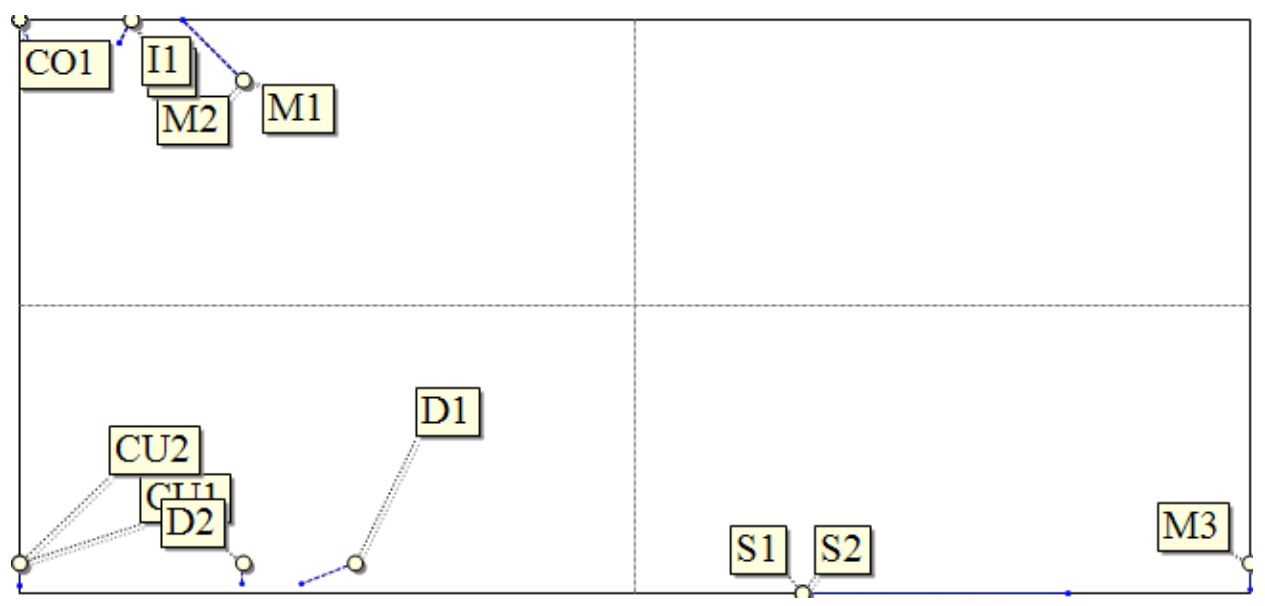

Fig 8 The direct/indirect displacement map

This plan, represented in Figure 8, shows the displacement of the influences of the factors which designates the change of the degrees of influence between the direct and indirect plans of the influences/dependencies. The results of the direct and indirect influences/dependencies analysis can be classified according to a comparison between the driving and dependent factors at the direct and indirect levels, as shown in Table 14. We note that all the factors kept their same position in the quadrants of the influence and dependency maps despite the variation in their degrees of influence.

Table 14. Classification of factors according to their dependencies on other factors

\begin{tabular}{lll}
\hline & Dependent factors & Independent factors \\
\hline Direct classification & $\mathrm{M} 3, \mathrm{~S} 1, \mathrm{~S} 2$ & $\mathrm{M} 1, \mathrm{M} 2, \mathrm{I} 1, \mathrm{I} 2, \mathrm{CO} 1$ \\
Indirect classification & $\mathrm{M} 3, \mathrm{~S} 1, \mathrm{~S} 2$ & $\mathrm{M} 1, \mathrm{M} 2, \mathrm{I} 1, \mathrm{I} 2, \mathrm{CO} 1$ \\
Intersection & $\mathrm{M} 3, \mathrm{~S} 1, \mathrm{~S} 2$ & $\mathrm{M} 1, \mathrm{M} 2, \mathrm{I} 1, \mathrm{I} 2, \mathrm{CO} 1$ \\
\hline
\end{tabular}

\section{$4 \quad$ Results and discussions}

The aim of this study is to analyze and develop a model of mutual influences and relationship among factors allowing the assessment of reconfigurability. First, 12 quantitative factors were identified based on the literature. They were chosen based on each characteristic (modularity, integrability, convertibility, diagnosability, scalability and customization) in order to facilitate their quantitative evaluations. To develop the SSIM matrix, a questionnaire was given to 11 experts and academics to determine the influences of all the identified factors. Then, the MICMAC analysis presents substantial information on the importance and interdependencies of these factors.

The TISM results show that the number of modules (M1), the number of inter- and intra-modules (M2), the number of nodes (I1), the number of connections (I2) and the supply chain redundancy (CO1) are factors that affect the other factors, but they are not influenced by any other factor. In fact, they influence the factors of the highest-level including supply chain visibility (D1) and detection time (D2) that affect the factors of the second level: response time (CU1) and number of customized function (CU2). The highest level is composed of lead time, latency and throughput capacity that represent factors not influencing any other factor. These findings were verified and validated by the MICMAC analysis. Based on the results obtained by the direct and indirect classifications according to the driving power and the dependency levels (M1, M2, I1, I2, CO1) are independent factors, while $\mathrm{S} 1, \mathrm{~S} 2$ and $\mathrm{M} 3$ are dependent factors.

The reconfigurability of supply chains can be related to two main structural and functional aspects. The structural aspect consists in changing the structure of the supply chain related to its design nature. On the other hand, the functional aspect is related to value creation aiming at improving the supply chain functions (purchasing, storage, flow management, etc.). Indeed, M1, M2, I1, I2 and CO1 are factors related to the structural design changes of the supply chain. Thus, modularity, integrability and convertibility are characteristics that affect the components of the supply chain: the nodes, which represent suppliers, factories, distribution centers, etc., and the connections that 
designate the information and physical flows linking the nodes. These elements (nodes and connections) form the structural design of the supply chain. Figure 9 shows the interactions between the reconfigurability characteristics based on their evaluation factors.

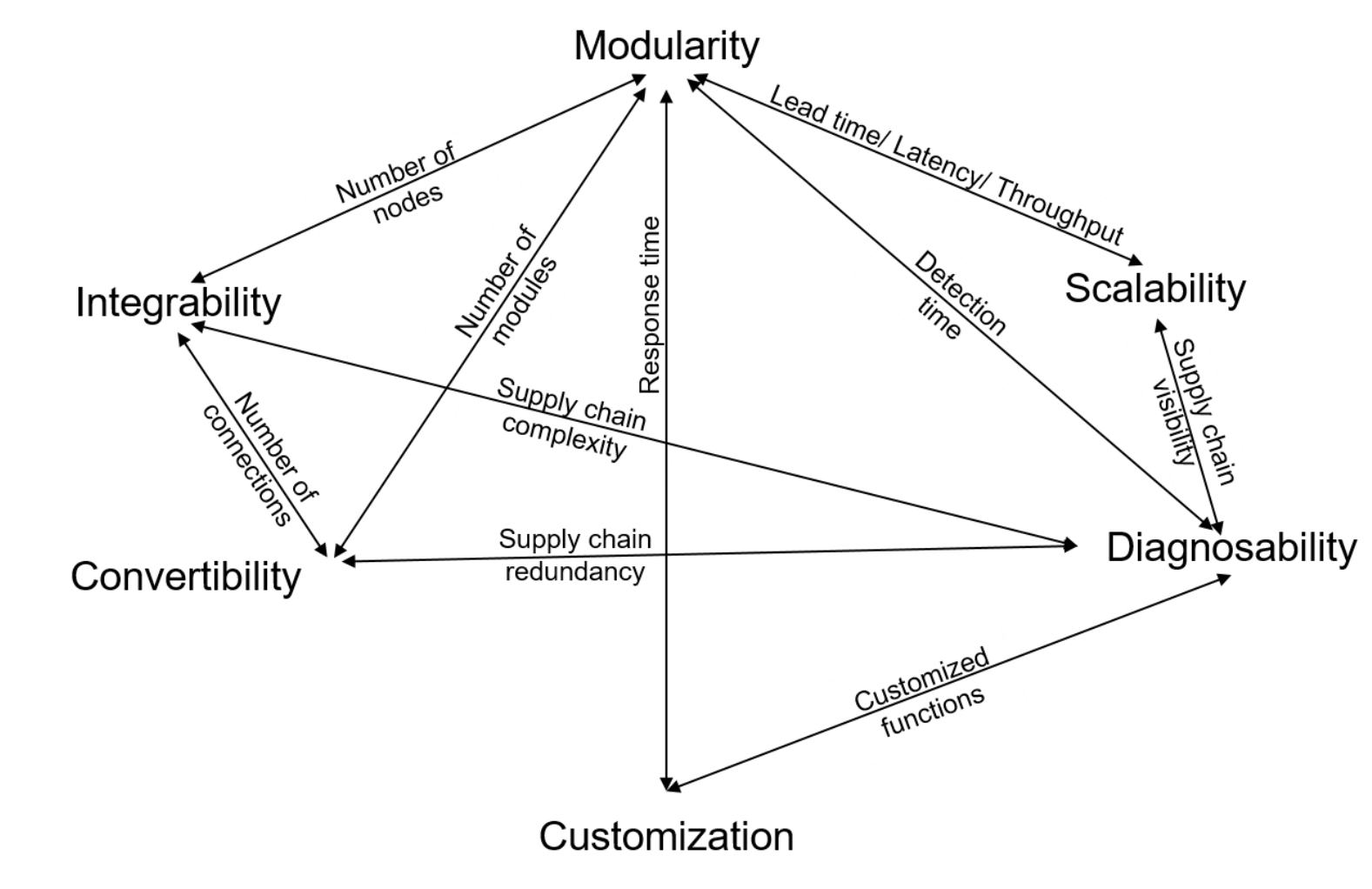

Fig 9 Representation of the relationships between the characteristics of supply chain reconfigurability

\section{$5 \quad$ Managerial implications}

The aim of this study is to identify and analyze the quantitative factors considered to evaluate the reconfigurability in supply chains. This analysis allows managers and decision makers to know the most important factors in both the evaluation and implementation of reconfigurability. Indeed, these factors were identified, in the literature, according to the six characteristics of reconfigurability (modularity, integrability, convertibility, diagnosability, scalability and customization). They also allow successfully implementing a RSC.

The factor analysis helped prioritize and classify the quantitative factors and consequently the reconfigurability characteristics. Indeed, the number of modules, the number of intra- and inter-module interactions, the number of nodes and the number of connections between them as well as the supply chain redundancy represent the independent factors that influence the other factors. These factors show the importance of modularity, integrability and convertibility in designing a RSC. These characteristics mainly impact the structural change of the supply chain. Indeed, improving the supply chain degree of reconfigurability requires modular design, reducing the degree of complexity, which depends on the number of nodes and connections, and increasing the redundancy of the supply chain. On the other hand, the supply chain visibility, related to the quantity and quality of the information shared between all the actors of the chain, and the detection time depend highly on the supply chain structure. Indeed, the less complex the supply chain is, the higher the visibility and the faster the detection time of failures will be. In addition, factors related to customization (response time and number of customized functions) depend on the supply chain structure. Thus, the modular design must be oriented towards mass customization. Finally, lead time, latency and throughput capacity are factors influenced by other factors and do not influence other factors. This classification allows understanding the impact of each factor on the evaluation of the supply chain reconfigurability and how to improve its degree through structural and functional changes. 


\section{Conclusion}

Supply chain reconfiguration has recently become a crucial strategy to cope with disruptions and adapt to new market needs. The success of the reconfiguration strategy depends on ensuring its six characteristics (modularity, integrability, convertibility, diagnosability, scalability and customization) that reduce the reconfiguration effort.

In this paper, the quantitative factors enabling to evaluate the degree of reconfigurability were identified from the literature and analyzed using the TISM approach and the MICMAC analysis. The influence of the identified factors on each other was studied to prioritize them. In fact, twelve factors related to the six previously mentioned characteristics were examined. Their influence was shown using a questionnaire that allowed constructing the influence matrix of the TISM approach. Based on the results obtained by the latter, the factors were classified into 4 levels according to their influences. Indeed, the number of modules, the number of intra- and inter-module interactions, the number of nodes and the number of connections between them and the supply chain redundancy are the factors that influence other factors, but they are not influenced by them. This prioritization of factors was verified and validated by the MICMAC analysis through direct and indirect classifications of influences between factors. On the other hand, by interpreting these results, the characteristics were classified into two aspects (structural and functional). Modularity, integrability and convertibility are related to the structural aspect, i.e., they allow changing essentially the design structure of the supply chain. However, the functional aspect of the RSC depends mainly on diagnosability, scalability and customization.

The proposed model allowed classifying the quantitative factors evaluating the six reconfigurability characteristics according to their influence on each other. However, the attribution of weights to each characteristic in the evaluation of the degree of reconfigurability cannot be assigned using our model. Indeed, the importance of the characteristics changes as a function of the sector, the market disruptions, the customers' requirements, etc. In future work, we will focus on the importance of each characteristic in the reconfigurability assessment process by taking into consideration their influence on each other. 


\section{Declarations}

\subsection{Funding}

No funding was received to assist with the preparation of this manuscript.

\subsection{Conflicts of interest}

The authors have no conflicts of interest to declare that are relevant to the content of this article.

\subsection{Availability of data and material}

The authors have no data or supplementary material to declare but the data will be made available to reviewers if necessary. The authors confirm that the data supporting the findings of this study are available in the article.

\subsection{Code availability}

No code to declare.

\subsection{Ethics approval}

Not applicable.

\subsection{Consent to participate}

Not applicable.

\subsection{Consent for publication}

Not applicable 


\section{References}

1. Barbieri P, Elia S, Fratocchi L, Golini R (2019) Relocation of second degree: Moving towards a new place or returning home? Journal of Purchasing and Supply Management 25:100525. https://doi.org/10.1016/j.pursup.2018.12.003

2. Robinson PK, Hsieh L (2016) Reshoring: a strategic renewal of luxury clothing supply chains. Oper Manag Res 9:89-101. https://doi.org/10.1007/s12063-016-0116-x

3. Barbieri P, Boffelli A, Elia S, et al (2020) What can we learn about reshoring after Covid-19? Oper Manag Res 13:131-136. https://doi.org/10.1007/s12063-020-00160-1

4. Strange R (2020) The 2020 Covid-19 pandemic and global value chains. J Ind Bus Econ 47:455-465. https://doi.org/10.1007/s40812-020-00162-x

5. Essex A, Subramanian N, Gunasekaran A (2016) The relationship between supply chain manager capabilities and performance: empirical evidence. Production Planning \& Control 27:198-211. https://doi.org/10.1080/09537287.2015.1091519

6. Zidi H, Hamani N, Laajili C, Benaissa M (2021) A reconfiguration approach for a supply chain tracking platform. International Journal of Shipping and Transport Logistics: INDERSCIENCE PUBLISHERS

7. Dolgui A, Ivanov D, Sokolov B (2018) Ripple effect in the supply chain: an analysis and recent literature. International Journal of Production Research 56:414-430. https://doi.org/10.1080/00207543.2017.1387680

8. Olivares-Aguila J, ElMaraghy W (2020) System dynamics modelling for supply chain disruptions. International Journal of Production Research 0:1-19. https://doi.org/10.1080/00207543.2020.1725171

9. He J, Alavifard F, Ivanov D, Jahani H (2019) A real-option approach to mitigate disruption risk in the supply chain. Omega 88:133-149

10. Ho W, Zheng T, Yildiz H, Talluri S (2015) Supply chain risk management: a literature review. International Journal of Production Research 53:5031-5069. https://doi.org/10.1080/00207543.2015.1030467

11. Hosseini S, Ivanov D, Dolgui A (2019) Review of quantitative methods for supply chain resilience analysis. Transportation Research Part E: Logistics and Transportation Review 125:285-307. https://doi.org/10.1016/j.tre.2019.03.001

12. Torabi SA, Baghersad M, Mansouri SA (2015) Resilient supplier selection and order allocation under operational and disruption risks. Transportation Research Part E: Logistics and Transportation Review 79:22-48. https://doi.org/10.1016/j.tre.2015.03.005

13. Slepniov D, Waehrens BV, Jørgensen C (2010) Global operations networks in motion: Managing configurations and capabilities. Oper Manag Res 3:107-116. https://doi.org/10.1007/s12063-010-0032-4

14. Dolgui A, Ivanov D, Sokolov B (2020) Reconfigurable supply chain: the X-network. International Journal of Production Research 58:4138-4163. https://doi.org/10.1080/00207543.2020.1774679

15. Tziantopoulos K, Tsolakis N, Vlachos D, Tsironis L (2019) Supply chain reconfiguration opportunities arising from additive manufacturing technologies in the digital era. Production Planning \& Control 30:510 521. https://doi.org/10.1080/09537287.2018.1540052

16. Chandra C, Grabis J (2016) Supply Chain Configuration: Concepts, Solutions, and Applications, 2nd ed. Springer-Verlag, New York 
17. Biswas $\mathrm{P}$ (2017) Modeling reconfigurability in supply chains using total interpretive structural modeling. $\mathrm{J}$ of Advances in Mgmt Research 14:194-221. https://doi.org/10.1108/JAMR-09-2016-0071

18. Kelepouris T, Wong CY, Farid AM, et al (2006) Towards a Reconfigurable Supply Network Model. In: Intelligent Production Machines and Systems. Elsevier, pp 481-486

19. Zidi S, Hamani N, Kermad L (2021) Use of fuzzy logic for reconfigurability assessment in supply chain: Case study. Int. J. Fuzzy Syst. https://doi.org/ 10.1007/s40815-021-01187-7. In PROOF

20. Zidi S, Hamani N, Kermad L (2021) New metrics for measuring supply chain reconfigurability. J Intell Manuf. https://doi.org/10.1007/s10845-021-01798-9

21. Maganha I, Silva C, Ferreira LMDF (2018) Understanding reconfigurability of manufacturing systems: An empirical analysis. Journal of Manufacturing Systems 48:120-130

22. Koren Y, Heisel U, Jovane F, AL ET (1999) Reconfigurable Manufacturing Systems. CIRP Annals 48, 2:527-540

23. Wiendahl HP, Heger CL (2004) Justifying Changeability. A Methodical Approach to Achieving Cost Effectiveness. Journal for Manufacturing Science and Production 6, 1-2:33-40

24. Setchi RM, Lagos N (2004) Reconfigurability and reconfigurable manufacturing systems: state-of-the-art review. 529-535

25. Mehrabi MG, Ulsoy AG, Koren Y (2000) Reconfigurable manufacturing systems: Key to future manufacturing | SpringerLink. Journal of Intelligent Manufacturing 11:403-419

26. Elmaraghy HA (2005) Flexible and reconfigurable manufacturing systems paradigms. International Journal of Flexible Manufacturing Systems 17, 4:261-276

27. Koren Y, Shpitalni M (2010) Design of reconfigurable manufacturing systems. Journal of Manufacturing Systems 29, 4:130-141

28. Wei H, Wang ETG (2007) Creating Strategic Value from Supply Chain Visibility- the Dynamic Capabilities View. 2007 40th Annual Hawaii International Conference on System Sciences 7-7

29. Cheng X, Wan C, Qiu H, Luo J (2019) A Measure for Modularity and Comparative Analysis of Modularity Metrics. In: Huang GQ, Chien C-F, Dou R (eds) Proceeding of the 24th International Conference on Industrial Engineering and Engineering Management 2018. Springer Singapore, Singapore, pp 266-277

30. Farid AM (2014) Measures of reconfigurability and its key characteristics in intelligent manufacturing systems. J Intell Manuf 28:353-369. https://doi.org/10.1007/s10845-014-0983-7

31. Gumasta K, Kumar Gupta S, Benyoucef L, Tiwari MK (2011) Developing a reconfigurability index using multi-attribute utility theory. International Journal of Production Research 49:1669-1683. https://doi.org/10.1080/00207540903555536

32. Haddou Benderbal H, Dahane M, Benyoucef L (2018) Modularity assessment in reconfigurable manufacturing system (RMS) design: an Archived Multi-Objective Simulated Annealing-based approach. Int J Adv Manuf Technol 94:729-749. https://doi.org/10.1007/s00170-017-0803-2

33. Hölttä K, Suh ES, de Weck O (2005) TRADEOFF BETWEEN MODULARITY AND PERFORMANCE FOR ENGINEERED SYSTEMS AND PRODUCTS. In: DS 35: Proceedings ICED 05, the 15th International Conference on Engineering Design, Melbourne, Australia, 15.-18.08.2005. https://www.designsociety.org/publication/23113/TRADEOFF+BETWEEN+MODULARITY+AND+PE RFORMANCE+FOR+ENGINEERED+SYSTEMS+AND+PRODUCTS. Accessed 18 Nov 2020 
34. Hölttä-Otto K, Chiriac NA, Lysy D, Suk Suh E (2012) Comparative analysis of coupling modularity metrics. Journal of Engineering Design 23:790-806. https://doi.org/10.1080/09544828.2012.701728

35. Wang GX, Huang SH, Yan Y, Du JJ (2016) Reconfiguration schemes evaluation based on preference ranking of key characteristics of reconfigurable manufacturing systems. Int J Adv Manuf Technol 89:22312249. https://doi.org/10.1007/s00170-016-9243-7

36. Bouaissi A, Allaoui H, Jean-Christophe N (2015) La modularité produit et chaîne logistique dans un contexte collaboratif et durable: revue de littérature et cadre conceptuel. In: Xème Conférence Internationale : Conception et Production Intégrées. Tanger, Morocco

37. Wolters MJJ (1999) The business of modularity and the modularity of buisiness. Selbstverl, Rotterdam

38. Voordijk H, Meijboom B, de Haan J (2006) Modularity in supply chains: a multiple case study in the construction industry. International Journal of Operations \& Production Management 26:600-618. https://doi.org/10.1108/01443570610666966

39. Maler-Speredelozzi V, Koren Y, Hu SJ (2003) Convertibility Measures for Manufacturing Systems. CIRP Annals 52:367-370. https://doi.org/10.1016/S0007-8506(07)60603-9

40. Chinnathai MK, Alkan B, Harrison R (2017) Convertibility Evaluation of Automated Assembly System Designs for High Variety Production. Procedia CIRP 60:74-79. https://doi.org/10.1016/j.procir.2017.01.005

41. Sheffi Y, Rice J James (2005) A Supply Chain View of the Resilient Enterprise. MIT Sloan Management Review 47:

42. Serdarasan S (2013) A review of supply chain complexity drivers. Computers \& Industrial Engineering 66:533-540. https://doi.org/10.1016/j.cie.2012.12.008

43. Serdarasan S, Tanyas M (2012) Dealing with Complexity in the Supply Chain: The Effect of Supply Chain Management Initiatives. Social Science Research Network, Rochester, NY

44. Nguyen H, Onofrei G, Harrison N, Truong D (2020) The influence of cultural compatibility and product complexity on manufacturing flexibility and financial performance. Oper Manag Res 13:171-184. https://doi.org/10.1007/s12063-020-00163-y

45. Beaulieu M (2000) Définir et maîtriser la complexité des réseaux de logistique à rebours

46. Caridi M, Crippa L, Perego A, et al (2010) Do virtuality and complexity affect supply chain visibility? International Journal of Production Economics 127:372-383. https://doi.org/10.1016/j.ijpe.2009.08.016

47. Luke E (1993) Defining and Measuring Scalability

48. Ball MO, Ma M, Raschid L, Zhao Z (2002) Supply chain infrastructures: system integration and information sharing. SIGMOD Rec 31:61-66. https://doi.org/10.1145/507338.507350

49. Durowoju O, Chan H, Wang X (2011) The impact of security and scalability of cloud service on supply chain performance. Journal of Electronic Commerce Research 12:

50. Zebardast M, Malpezi S, Taisch M (2013) Mass Customization in Supply Chain Level: Development of a Conceptual Framework to Manage and Assess Performance. In: Prabhu V, Taisch M, Kiritsis D (eds) Advances in Production Management Systems. Sustainable Production and Service Supply Chains. Springer Berlin Heidelberg, Berlin, Heidelberg, pp 81-90

51. Chandra C, Kamrani A (2004) Mass Customization. Springer US, Boston, MA 
52. Graman GA (2010) A partial-postponement decision cost model. European Journal of Operational Research 201:34-44. https://doi.org/10.1016/j.ejor.2009.03.001

53. Medini K (2013) Enterprise performance evaluation in the context of sustainable mass customization 